\title{
Embedded Assessment Tools for Maker Classrooms: A Design-Based Research Approach
}

\begin{abstract}
Maker-centered learning in schools has grown rapidly in recent years. The existing system and structure of schooling calls for a new form of assessment that complements the pedagogical values of making while also balancing the creative making practices driven by a maker's interest and curiosity. Current assessment approaches often do not meet the needs in assessing the multifaceted learning and development that occur during the process of making and learning. This research paper reports on the design of embedded assessment tools that can be adapted within school-based maker programs to enable embedded assessment of maker competencies, and describes how maker assessment can move beyond rubrics and portfolios.
\end{abstract}

Keywords: Making and makerspaces; Assessment; Classrooms; Design-Based Research

\section{Introduction}

Maker education - often seen as open-ended, creative exploration, manifesting as hands-on activities that cross domains and materials, including digital fabrication, textiles, 3D printing, crafts, and robotics - is believed by many to be a compelling approach that can spark and sustain students' interests and support development of the necessary skills for STEM fields (Sheridan, Halverson, Litts, Brahms, Jacobs-Priebe, \& Owens, 2014). Additionally, many maker education advocates claim that making can support students' learning beyond STEM content and skills, including dispositions such as autonomy (Quinn \& Bell, 2013), problem-solving and sensemaking (Martin, 2015), playful attitudes, and a failure-positive mindset (Dougherty, 2013; Martin, 2015). These outcomes are particularly valuable for the future generations to succeed in a 21st-century global economy that demands individuals who can think critically and creatively, use evidence to support their solutions to complex problems, and communicate clearly (Bybee \& Fuchs, 2006; Florida, 2002; Friedman, 2005). Not surprisingly, there is a growing interest among educators in bringing the maker movement into schools.

Bringing making into the K-12 school system, however, poses inevitable challenges. Several characteristics of traditional school methods are at odds with the interest-driven nature of maker movement (Godhe, Lilja, \& Selwyn, 2019). First, to incorporate making within a school curriculum, teachers must consider how certain academic standards could be "covered" through making. Second, given that almost all schools in the U.S. have grading system that requires summative assessment, school-based maker educators still need to figure out ways to assign grades for student work, even if they do not personally believe a grade is sufficient for creative work, judged purely by the product at the end. Third, teachers who advocate for maker education still must justify their initiatives and provide evidence to school and district administrators, "proving" how investments in makerspaces can help student learning beyond simple student excitement and enjoyment. Fourth, teachers often try to incorporate activities that are quick and easy, by fitting them into existing curriculum, often opting in for activities that can be done with relatively little effort but do not lead to engagement with more complex ideas and projects, which Blikstein (2013) calls "keychain" activities.

In addition to the practical and logistical challenges, the nature of making, especially when properly implemented, also conflicts with conventional assumptions made about assessment. First, making often includes collaboration (Clapp et al. 2017). Not only do students explicitly collaborate on maker projects, but they also share resources, help each other with finding resources and materials, share knowledge to troubleshoot, build on each other's ideas, and support iteration of each other's project. Therefore, assessing "individual student learning" in this context, by design, can undermine the dynamic and social nature of maker learning. Second, the maker process is often exploratory (Wardrip \& Brahms, 2015). Therefore, assessment of making should afford multiple pathways to completion, multiple goals, and multiple ways of expressing students' ideas because making projects, inherently student-driven, rarely have one right way. Third, making is often spatially distributed where students constantly interact with tools, materials, and equipment as they progress through their learning. Therefore, teachers are known to move about the space more frequently, floating among groups of students. Positioning the teacher as the "sole assessor" could limit the quantity and types of evidence that can be collected. Fourth, making is highly process-oriented and immersive; artificially reducing the process to small chunks of activity time disrupts the natural flow. As such, the assessment needs to be seamlessly woven into the process of making itself. Surveys or rubrics may not be able to capture authentic evidence for student learning. And finally, the learning and development that occurs in maker classrooms, related to such skills as agency, problem-solving, and risk-taking, are not easily measured by conventional assessment approaches. These competencies, sometimes called noncognitive competencies, social emotional learning competencies, character skills, or 21 st century skills, have been recognized as an important skill set that influences academic achievement. The common strategy for capturing these personal qualities are self-reported questionnaires administered to students, questionnaires for teachers, or 
performance-based assessment tasks in highly controlled environments. Each has its strengths and shortcomings, but none fully solve the problem (Duckworth \& Yeager, 2015). In order to solve these numerous challenges, there needs to be a new form of assessment to better understand and support student learning in maker-centered activities.

\section{Theoretical framework: Embedded assessment}

This study explores a new form of assessment that is suitable for maker-centered learning in schools, using an embedded assessment framework. Embedded assessment refers to a form of assessment that is directly woven into the learning environments and activities, from online games to classrooms, so that student learning can be monitored and supported in real-time without interrupting the flow of learning (Shute, Ventura, Bauer, 2009, 2009; Wilson \& Sloane, 2000). Embedded assessment has been widely adopted in digital learning environments, such as simulations and video games, where tasks are designed within a system to elicit evidence of desired outcomes, and to automatically and rapidly capture and rich process data. With well-designed embedded assessments in place, students' actions within a makerspace can provide robust evidence for underlying competencies, and the distinction between assessment and learning is blurred throughout continuous and iterative making process. Leveraging this theory and practice of embedded assessment, the present study aims to create a set of tools that enables embeddedness of assessment of maker learning processes. To create a tool that is both grounded in the theory of embedded assessment as well as attuned to the practical needs of teachers, involving their inputs as co-designers, we turned to a design-based research approach that addresses the question of What should assessment in maker-centered learning look like, beyond rubrics and portfolios?

In the present paper, we report on the first design cycle of the assessment tools by (a) reviewing the design narrative created by the research team that includes observation notes from design workshops, designers notes, and teacher interviews, (b) illustrating the design product created from this process and how design constraints were addressed, (c) introducing teachers' adaptation and implementation of the assessment tools, and (d) discussion of the design implications identified in this first design cycle.

\section{Method}

The present study takes a design-based research (DBR) approach to iteratively develop tools that enable embedded assessment in maker classrooms by working with teachers as co-designers (Roschelle \& Penuel, 2006). DBR is a research approach that improves educational practices through an iterative process of designing, developing, implementing, and analyzing an intervention, while allowing researchers to create generalizable theories of learning or design principles. DBR enabled the research team to investigate design theories for maker assessment while simultaneously developing and iterating on assessment tools for maker-centered classrooms. Our primary sources of data are the design notes, interview transcripts, and observation and meeting notes from that design workshops we ran with two collaborating middle schools, one in Portola Valley, CA, and one in Charlottesville, VA. The five total design workshops (each workshop was one- or two-days in duration) were conducted with nine teachers and four coaches in total; the aim was to collaboratively develop assessment tools and methods of implementation in their respective classrooms. During the first two workshops at each partner school, we focused on collecting information about teachers' existing assessment practices while also prototyping how our assessment approach could be integrated into their maker curriculum. The latter three workshops focused on collecting feedback from teachers, specifically on early prototypes of tools. Throughout this phase, the team recorded 1:1 interviews, phone calls, and meeting notes that informed design narratives and the design of assessment tools. The research team also interviewed teachers after rounds of implementation, in order to understand how they adapted and implemented the assessment tools in their classrooms. The design implications that emerged from these processes are discussed.

\section{Design narrative}

The goal of this project was to create assessment tools that can enable seamless integration of assessment into the maker activity, similar to how it is achieved in digital games or simulations, without interrupting the flow of maker learning. Based on the theory and practices of embedded assessment in both classrooms (Wilson \& Sloane, 2000) and digital environments (Shute et al., 2009), the research team hypothesized that the overall experience of assessment in making should be (a) embedded, (b) construct-driven, and (c) evidence-based (Table 1).

Table 1: Definitions of the criteria of embedded assessment in making drawn from literature 


\begin{tabular}{|l|l|}
\hline Construct-driven & $\begin{array}{l}\text { School-based making faces the challenges and tensions inherent in bridging open- } \\
\text { ended, learner-driven maker approaches that meaningfully support valued skills and } \\
\text { dispositions with the need to meet strict academic standards and testing requirements. } \\
\text { Therefore, assessment of making should be flexible and allow learners and teachers to } \\
\text { understand what the intended competencies are. }\end{array}$ \\
\hline Evidence-based & $\begin{array}{l}\text { Assessment should allow for multiple forms of evidence to be collected across } \\
\text { multiple time points, and refer to tangible and visible evidence generated in process of } \\
\text { making. }\end{array}$ \\
\hline
\end{tabular}

In addition, the following design constraints (Table 2) emerged from the interviews conducted during the design workshops.

Table 2: Definitions of the criteria of assessment drawn from teacher interviews

\begin{tabular}{|l|l|}
\hline Connecting with artifacts & $\begin{array}{l}\text { Assessment should enable students to connect the artifacts that they } \\
\text { create with concrete skills. }\end{array}$ \\
\hline Reflection with students & $\begin{array}{l}\text { Assessment should enable teachers and students to have } \\
\text { conversations that support students to reflect upon their making } \\
\text { processes, supported by concrete evidence. }\end{array}$ \\
\hline Shouldn't take too much time & $\begin{array}{l}\text { Assessment should not take too much time during classes or for } \\
\text { processing afterwards. }\end{array}$ \\
\hline Increase student awareness & $\begin{array}{l}\text { Assessment should raise student awareness of their own learning } \\
\text { (i.e. what are they learning from the given activity?) }\end{array}$ \\
\hline $\begin{array}{l}\text { Helps students and teachers understand } \\
\text { diverse learning progress }\end{array}$ & $\begin{array}{l}\text { Assessment should help teachers and students to realize different } \\
\text { learning avenues and outcomes associated with the activity at hand. }\end{array}$ \\
\hline $\begin{array}{l}\text { Tap various outcomes beyond content } \\
\text { knowledge }\end{array}$ & $\begin{array}{l}\text { Assessment should give students opportunities to showcase their } \\
\text { content knowledge AND other maker-related skills. }\end{array}$ \\
\hline Participatory & $\begin{array}{l}\text { Assessment should empower students to capture evidence of their } \\
\text { own learning within the dynamic processes of making, whether for } \\
\text { themselves or for one another. }\end{array}$ \\
\hline
\end{tabular}

Building on these insights from the embedded assessment literature as well as the values and challenges presented by teachers, we developed a first prototype of the embedded assessment toolkit.

\section{Design product: Embedded assessment toolkit}

The toolkit includes seven tools that teachers can adapt to their maker projects. Each tool helps teachers to conduct one of the three pillars of work that ensure that assessment is embedded within makerspaces: context setting, evidence collection, and meaning making.

\section{Context setting}

Context setting is a process that aims to create a shared understanding of what the constructs are (i.e. what maker competencies are you striving for?), familiarizing students with learning goals and the process of assessment so that they themselves can collect, reflect, and share their own evidence for learning in the moment. Teacher interviews revealed one of the important design constraints: the challenge and desire to involve students as active participants in the assessment process, not just as receivers of assessment from their teacher. Tools in this category aim to help students and teachers develop a shared language of learning goals and practice the process of capturing learning together.

Maker Elements is a tool intended to communicate the learning that can happen when making, aimed at supporting middle school students to understand what the identified constructs (in this case, "elements") mean. We identified a set of skills or practices that are well-supported in the maker learning literature (e.g. Bevan, Gutwill, Petrich \& 
Wilkinson, 2015; Clapp, Ross, Ryan, \& Tishman, 2016; Wardrip \& Brahms, 2015) and introduced them as Maker Constructs. During the design workshop sessions, teachers discussed and modified the list based on what they deemed to be the most compelling and relevant for school contexts. The team further explored definitions of and ways in which students could make sense of the constructs. For example, teachers suggested that we incorporate "I" statements to help students understand the constructs in their own contexts (Figure 1).

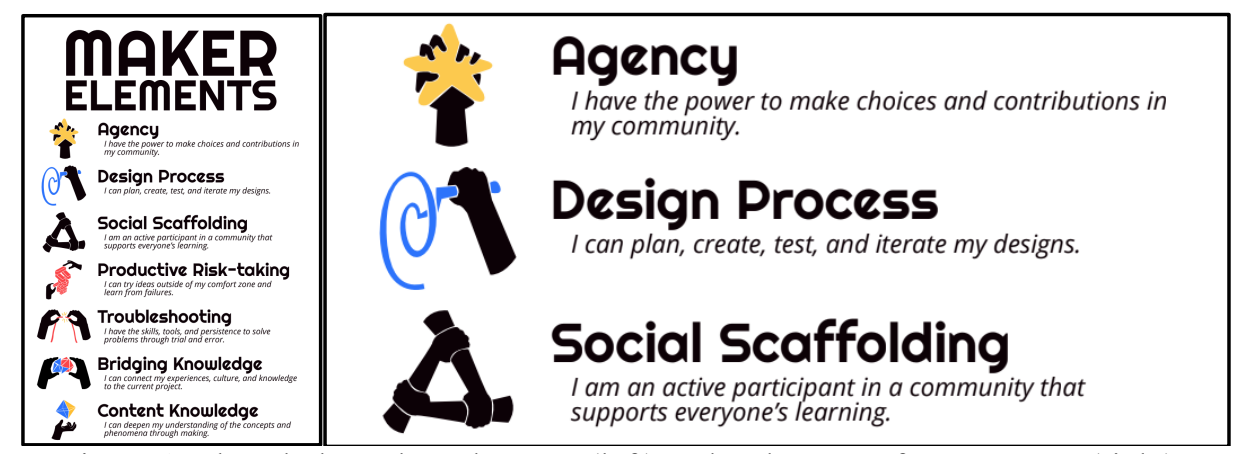

Figure 1. The whole Maker Elements (left) and a close-up of I statements (right).

With Maker Elements in place, teachers also discussed the need for an activity that enables students to discuss the meaning of each element and think about what evidence could look like. Teachers expressed a concern that many of their students were not familiar or comfortable with thinking about these skills in schools, highlighting a need to introduce the terminology and skills in a non-intimidating way. We created an activity, Superpower Hour, to address this concern.

Superpower Hour is a playful activity that introduces maker elements through a craft activity to students. In this activity, students read a short story about real-life innovators, identifying the Maker Elements in each individual's life journey. They then create a cape for the innovator that represents the Maker Elements found in the life story (Figure 2).

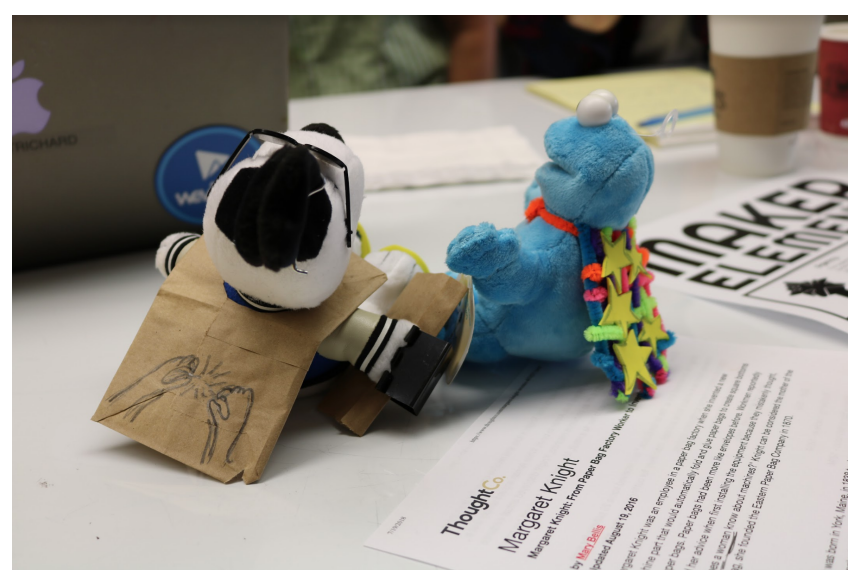

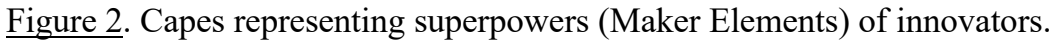

\section{Evidence collection}

While generating and capturing visible and tangible evidence throughout learning is an essential goal of any assessment, it is particularly crucial for maker education where learning centers around hands-on activities and social interactions and lead to various forms of evidence of learning at multiple points throughout the process. Due to this nature, it is challenging for teachers to capture in-the-moment evidence. Such visible and tangible evidence would allow students to see and monitor their own progress, giving a visible shape to usually-invisible and abstract constructs. In addition, these forms of evidence can persist beyond the moment of making and can be shared with stakeholders who need to see student progress over time. Therefore, process-focused evidence collection tools are needed to make the internal state of a learner (e.g. ideas, questions, struggles, feelings, or inspirations) visible. 
Maker Moments is a peer- or self-assessment tool resembling a customizable bingo-like worksheet, where students can notate moments in which they exhibit or practice up to three Maker Elements (Figure 3). It works best with indicators that are easily observable and quantified (e.g., the number of risk-taking, the number of iterations, etc.) The tool provides opportunity for students to recognize behaviors associated with the Maker Elements and keeps a snapshot of behaviors from each day over the course of a day, week, or project. At a quick glance, students and teachers can, for example, see that a group had a "collaborative" day but weren't very "risk$y$ " based on the number of moments documented. At the end of a week or project, the data can be graphed or discussed, potentially surfacing the changes over time. To supplement this quantitative evidence marked by the students, teachers have the option to add a reflection question to the card to capture a quick reflection based on the evidence at the end of the class session.

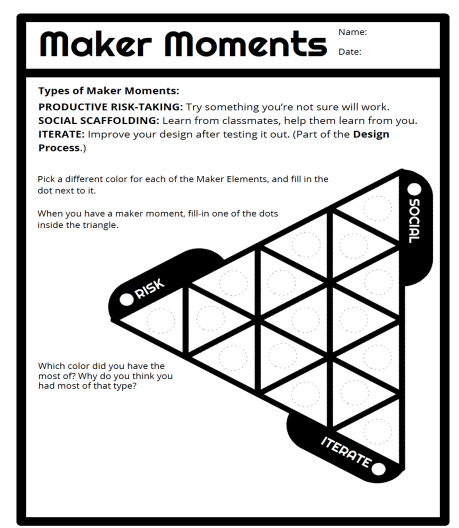

Figure 3. Maker moment worksheet.

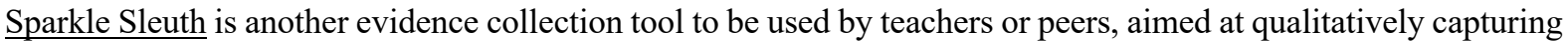
moments of learning (or moments of "sparkle"). It is a set of paper slips, upon which teachers or peers write observation-based comments about a student's actions during a project or activity. These comments offer immediate but unobtrusive feedback in a form of acknowledgement. Sparkle Sleuth can be used in combination with Maker Moments, for example, to have both quantitative and qualitative data for teachers and students to collectively reflect on those moments.

Stuck Station is a standalone video recording station that students use during moments when they are "stuck" on their project. Regardless of whether the issue is technical (e.g., an LED does not workt, a tower is tipping over) or social (e.g., conflict with a group member, can't make a decision), the station helps students explore strategies to get unstuck by allowing them to talk through the problem at the video recording station. Students are encouraged to visit the station when they come up against an issue in their work; the station provides an opportunity to walk away, talk through the project, and then return with new ideas or reflective thoughts. At the end of the class session, students revisit their "stuck" moment, and write down how they worked through the issue, whether their attempts were successful, or what they will do next. The tool also comes with a series of small tips, called Unstuck Tips (Haduong \& Brennan, 2018), that students may use as reflection prompts, as well as an exit ticket that assists in their problem identification and goal setting (Figure 4).

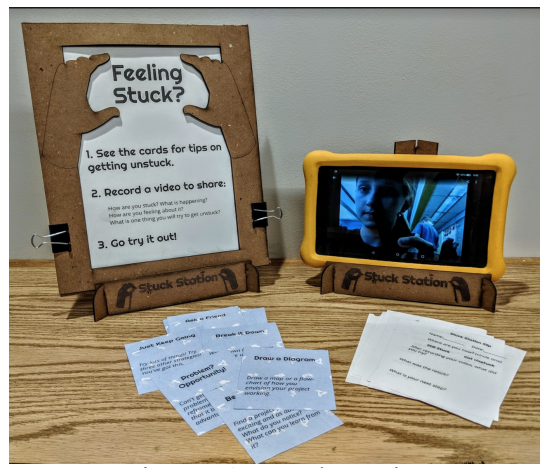

Figure 4. Stuck station. 


\section{Meaning making}

After evidence is collected, teachers and students must construct understanding about student learning based on the evidence. They must also share those understandings, whether as feedback in the classroom or in communicating with stakeholders interested in the learning. We call this process "meaning making," where students and teachers work together to construct meaning from the collected evidence. While each individual evidence collection tool can be used as a reflection tool throughout a project, this process looks at making meaning from evidence collected over time (a project, course, or year).

Field Guide is a tool for curating the collected evidence in order to show student progress and achievements. Field Guide is a binder where students can store and organize all evidence collected and identify pieces of evidence that are exemplars of their performance. Students can revisit evidence that was collected over multiple class periods, developing a narrative or storyboard that shows their growth (we call this hatching, emerging, and soaring, imitating field guides of birds) for each element. They can classify the evidence into levels based on their solo reflections, group conversations, or one-on-one meetings with a peer or teacher. As time progresses and new Maker Elements are introduced, teachers and students gain a better understanding of the Elements and how they are visible in student work.

\section{Design implementation}

Embedded assessment requires careful adaptation to the contexts of classrooms (Wilson \& Sloane, 2000). Thus, to formatively evaluate the overall usability of our tools, it is important to understand how teachers customized the tools based on the needs of their classrooms and audiences. Below we showcase several examples of tool adaptations, as well as teacher reflections on those experiences.

\section{Maker Elements}

Teachers at both schools printed out the full Maker Elements poster as-is, and hung it in classrooms in highly visible locations (Figure 5, right). On another level, teachers in Charlottesville chose one construct per unit and inserted a sheet about the construct into each student's binder cover, encouraging and reminding students to focus on that specific one (Figure 5, left). In both examples, teachers visibly displayed the tool to remind and draw students' attention to the constructs pertinent to the activities. One teacher shared that she saw this approach start to work when one of her students used the word "troubleshooting" to describe how she helped her family to solve a problem. Teacher feedback highlighted the importance of assessment to be embedded across and beyond activities; the more the elements and tools were commonly used, the more familiar and comfortable students became, developing understanding and ability to demonstrate, capture, and communicate their learning in those terms.

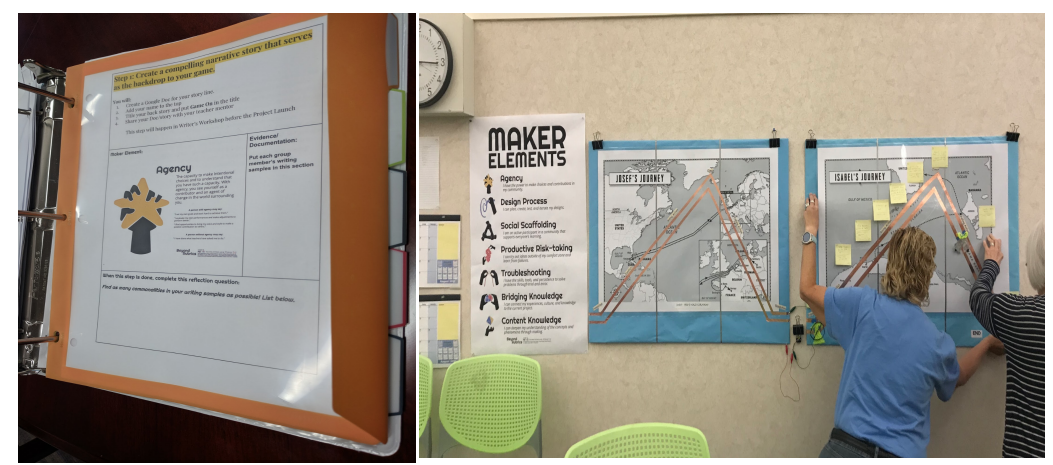

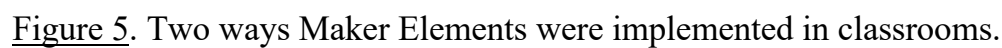

\section{Sparkle Sleuths}

Several teachers customized Sparkle Sleuths: differing the paper slips to add more contextual data (e.g., name, date, time), writing in more detail, or using Instax photos to add images to the documentation. A pattern we saw across types of implementation were that all teachers added more information about student performance than intended in the original design of the tool. For example, one teacher added student names and activities to the slip, allowing for easier sorting (Figure 6, left); one teacher wrote down more detailed descriptions, intended to be shared with students (Figure 6, middle); and other teachers included photographs, helping to recall what the visible action looked like (Figure 6, right). A teacher from Charlottesville pointed out that Sparkle Sleuth was useful for keeping track of learning experiences that would otherwise be forgotten: "[I] Really liked the tool because if I give a student feedback, as soon as I walk away, the student will forget those things. The tools, especially the slips 
and taking photos, gives you something to think back on and reflect and keep, which is cool". Though the logistical difficulties of documentation while lead an activity continue to be a challenge, these experiences demonstrated that documenting observations of learning and making is crucial for assessment.

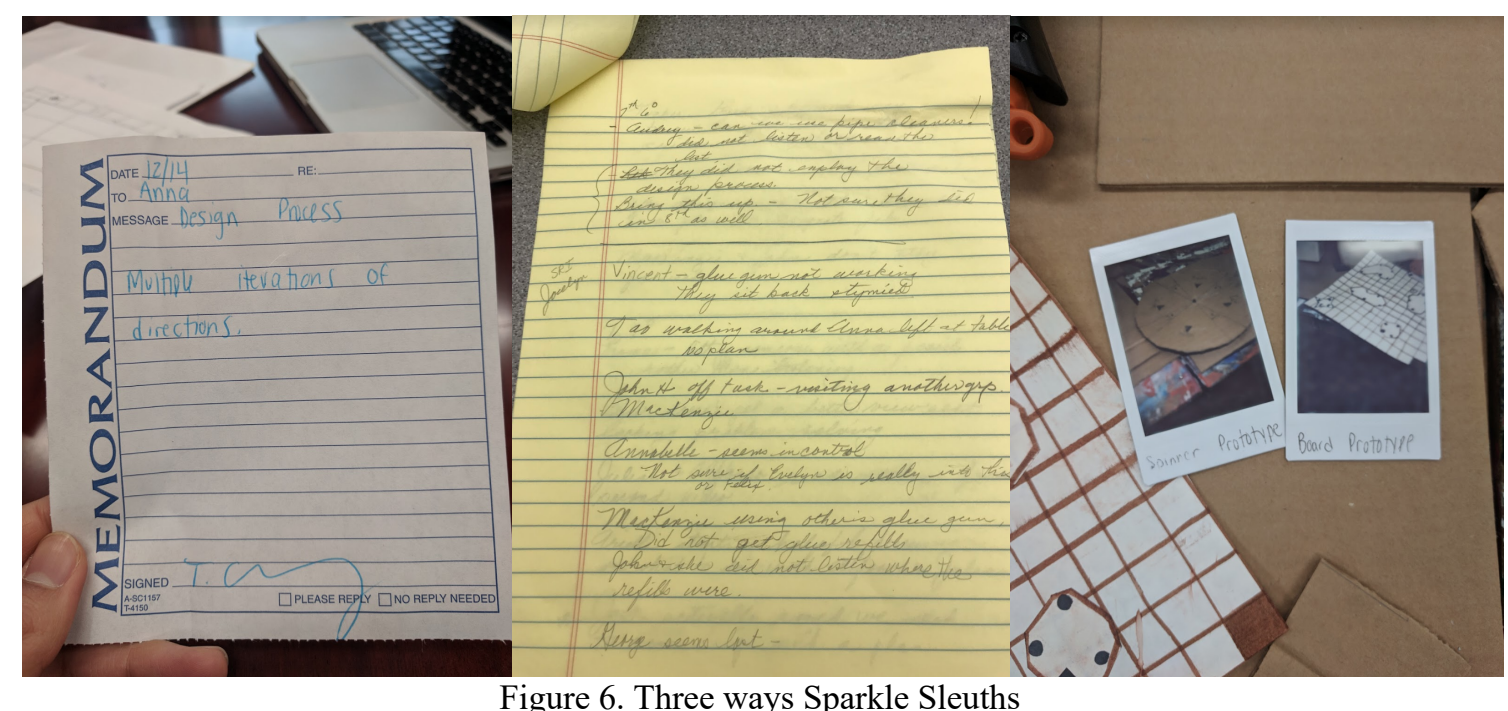

\section{Maker Moments}

A teacher from Portola Valley chose to combine Sparkle Sleuth and Maker Moments, as she was concerned organizing and keeping track of multiple slips or sheets of paper (Figure 7). With class sizes of 20-25 students, she struggled with balancing the needs of implementing assessment and the needs of any classroom activity, especially those requiring tools and safety oversight. Wtih maker-centered learning, where students are often engaged in complex and dynamic activities, it is crucial that assessment tools are manageable and organizable by students themselves.

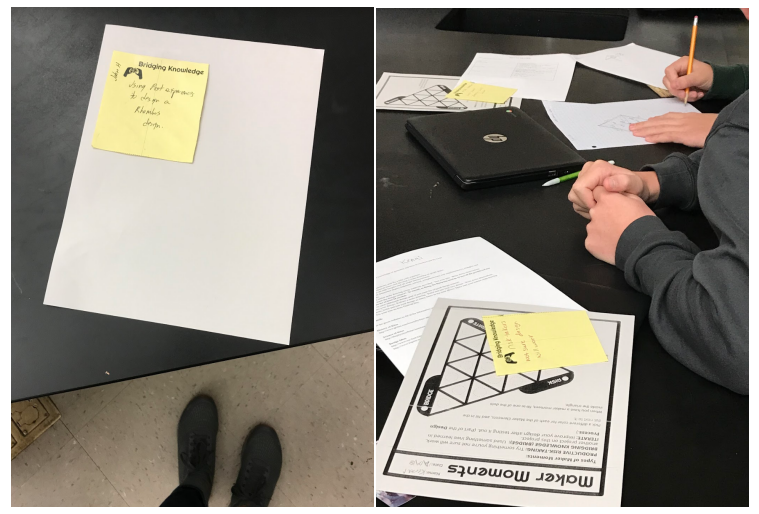

Figure 7. How Maker Moments were used in combination with Sparkle Sleuth.

\section{Discussion}

This paper demonstrates how the research team created a new form of assessment that could be used within school-based making, by leveraging the theory of embedded assessment and addressing design challenges unique to the context of school-based making. In particular, having teachers and students share the work and responsibility of collecting evidence and making meaning from the data was necessary not only for practical reasons but also highly valued by maker educators; it is aligns closely with the ideas of student agency, often a key value in maker education. It is also worth noting that the underlying tension between what making means (e.g. making as a creative process, agency, collaboration and sharing) and how assessment is typically interpreted within schools can be revisited when creating assessment tools that are flexible, social, and compatible with the iterative and messy process of maker learning. Additionally, while there are concerns regarding how schooling practices could "ruin" making by providing students with "prescribed curriculum" (Kafai, Fields, \& Searle, 2014), the co-design process revealed that maker educators value the key principles of making, and are striving to maintain those principles within the existing structures of school. Therefore, the present work also validates the importance of re-imagining assessment for maker education, supporting teachers to find the right balance between student-driven and system-driven learning. 


\section{Conclusion}

This paper shares the iterative process of designing assessment tools for maker education. There are several implications that we can draw from this design process. First, the consistent and collaborative nature of the interactions with teachers allowed for true design-based research and directly addressed the original needs that surfaced in initial and ongoing exploration and conversations about maker assessments. This was particularly important, as understanding teachers' current assessment practices and needs in the context of school-based making was crucial to create tools that reflect the teachers' desires. Second, the co-design process also allowed for constant feedback and confirmation, while leaving room for new or refined needs to surface. While limited, this design process and product illustrate how school-based making can go beyond existing assessment practices by embedding evidence collection in the process of making, balancing the tension between learner agency and intended learning outcomes. This paper contributes to the field by (a) demonstrating the iterative process of creating assessment tools by incorporating both the literature of assessment as well as the desires and needs of the classroom teachers and (b) showcasing how the design an innovative tool can push the boundaries of assessment.

\section{References}

Bevan, B., Gutwill, J. P., Petrich, M., \& Wilkinson, K. (2015). Learning through STEM-rich tinkering: Findings from a jointly negotiated research project taken up in practice. Science Education, 99(1), 98-120.

Blikstein, P. (2013). Digital fabrication and 'making' in education: The democratization of invention. FabLabs: Of machines, makers and inventors, 4, 1-21.

Bybee, R. W., \& Fuchs, B. (2006). Preparing the 21st century workforce: A new reform in science and technology education. Journal of Research in Science Teaching: The Official Journal of the National Association for Research in Science Teaching, 43(4), 349-352.

Clapp, E. P., Ross, J., Ryan, J. O., \& Tishman, S. (2016). Maker-centered learning: Empowering young people to shape their worlds. Hoboken, NJ: John Wiley \& Sons.

Dougherty, D. (2013). The maker mindset. In Design, make, play (pp. 25-29). London, UK: Routledge.

Duckworth, A. L., \& Yeager, D. S. (2015). Measurement matters: Assessing personal qualities other than cognitive ability for educational purposes. Educational Researcher, 44(4), 237-251.

Florida, R. (2002). The rise of the creative class and how it's transforming work, leisure, community and everyday life. New York, NY: Basic Books.

Friedman, T. (2005). The world is flat: a brief history of the globalised world in the 21st century. London, UK: Allen Lane-Penguin Books.

Godhe, A. L., Lilja, P., \& Selwyn, N. (2019). Making sense of making: critical issues in the integration of maker education into schools. Technology, Pedagogy and Education, 1-12.

Haduong, P., \& Brennan, K. (2018, February). Getting Unstuck: New Resources for Teaching Debugging Strategies in Scratch. In Proceedings of the 49th ACM Technical Symposium on Computer Science Education (pp. 1092-1092). ACM.

Kafai, Y., Fields, D., \& Searle, K. (2014). Electronic textiles as disruptive designs. Harvard Educational Review, 84, 532-556.

Martin, L. (2015). The promise of the maker movement for education. Journal of Pre-College Engineering Education Research (J-PEER), 5(1), 4.

Peppler, K., Maltese, A., Keune, A., Chang, S., \& Regalla, L. (2015). The maker ed open portfolio project: Survey of Makerspaces, Part II. Open Portfolios. Berkeley, CA: MakerEd.

Quinn, H., \& Bell, P. (2013). How designing, making, and playing relate to the learning goals of K-12 science education. In Design, Make, Play (pp. 35-51). London, UK: Routledge.

Roschelle, J., \& Penuel, W. R. (2006, June). Co-design of innovations with teachers: Definition and dynamics. In Proceedings of the 7th international conference on Learning sciences (pp. 606-612). International Society of the Learning Sciences.

Sheridan, K., Halverson, E. R., Litts, B., Brahms, L., Jacobs-Priebe, L., \& Owens, T. (2014). Learning in the making: A comparative case study of three makerspaces. Harvard Educational Review, 84(4), 505-531.

Shute, V. J., Ventura, M., Bauer, M., \& Zapata-Rivera, D. (2009). Melding the power of serious games and embedded assessment to monitor and foster learning. Serious games: Mechanisms and effects, 2, $295-$ 321.

Wardrip, P. S., \& Brahms, L. (2015, June). Learning practices of making: developing a framework for design. In Proceedings of the 14th international conference on interaction design and children (pp. 375-378). ACM.

Wilson, M., \& Sloane, K. (2000). From principles to practice: An embedded assessment system. Applied measurement in education, 13(2), 181-208. 